\title{
Extending the $2 \%$ rule: the effects of heavy internal tags on stress physiology, swimming performance, and growth in brook trout
}

\author{
Michael G Smircich ${ }^{1,2^{*}}$ and John T Kelly
}

\begin{abstract}
Background: The use of internal telemetry has greatly advanced fisheries research in the past two decades, permitting researchers to observe movements and distributions of organisms in their natural environment. For many years, the prevailing opinion has been that internal tags should not weigh more than $2 \%$ of the dry body weight of a fish. Some studies indicate that tags weighing up to $12 \%$ dry body weight do not have a negative effect on swimming performance, but few authors have examined impacts to fish physiology and health. This study investigated how tags greater than $2 \%$ body mass affected the mortality, tag retention, swimming performance, and physiological indicators of stress in brook trout (Salvelinus fontinalis Mitchill).

Results: No mortality was observed between treatment groups, but tag retention was lowest in the heavy tag treatment group in which $80 \%$ (12 fish) lost tags. Swimming performance and physiological indices of stress were not significantly impacted by tag mass. Fish tagged with heavy tags showed slower growth in the 3 weeks after tagging, but growth rates appeared to recover by the end of the study, although this result may be confounded by tag loss.

Conclusion: The results of this study suggest that for brook trout, the $2 \%$ rule is a highly conservative guideline that can be substantially extended but should not exceed $7 \%$ body weight due to concerns about tag retention.
\end{abstract}

Keywords: Tag retention, Biotelemetry, Acoustic tagging

\section{Background}

The development of biotelemetry technologies in recent decades has given biologists unprecedented insights into organismal behavior and ecology, permitting researchers to monitor animals in their natural habitat over long distances and time periods, without the need for direct, often intrusive, observation. Once a custom-made commodity [1], tags, tracking devices, and automatic loggers may now be purchased 'off the shelf' from numerous vendors with a host of increasingly sophisticated capabilities. Biotelemetry technology has been a particular boon to the study of marine and aquatic organisms that move so freely in conditions that are inhospitable to human observers. The easy availability of advanced tags has had a significant impact on the ability of researchers to study

\footnotetext{
*Correspondence: michael.smircich@uconn.edu

'Department of Biology and Environmental Science, University of New Haven, West Haven, CT, USA

${ }^{2}$ Current Address: Department of Ecology and Evolutionary Biology, University of Connecticut, Storrs, CT, USA
}

fishes under a variety of conditions [2]. As a result, the number of researchers using acoustic telemetry to investigate fish behavior and survival has increased considerably in recent years [3].

A critical assumption in biotelemetry studies is that the tagged sample is representative of the general population; therefore, it is imperative that the presence of the tag does not negatively influence the performance, physiology, or survival of the marked fish. The location of the tag, and the mechanism of attachment or implantation, may be injurious to the fish, or may impair normal movement, thus biasing the observations [4]. Common methods of internal transmitter attachment include intragastric and intraperitoneal implantation. Researchers must clearly understand the potential consequences associated with each tag attachment method prior to an experiment as internal tags that are not of the proper size relative to species may cause loss of tags and increased mortality, thus biasing the results of the study. 
Beyond the challenges of tag attachment, the primary concern for researchers using biotelemetry is tag burden, the ratio of transmitter weight to fish weight [5]. Most researchers adhere to the guideline that tags should not weigh greater than $2 \%$ of the body weight of the fish in air [3], a practice that is often referred to as the ' $2 \%$ rule'. Despite its ubiquity, the $2 \%$ rule is not fully credited to a single author or citation and appears to be the result of a general consensus based on several studies of buoyancy control in fishes published between 1966 and 1984. Initial morphological studies reported that the swim bladder of typical freshwater teleosts is about $7 \%$ of the body volume, and that these fish have the capacity to adjust approximately $25 \%$ of that total volume [6]. Based on these findings, it was argued that the maximum tag weight in water should not exceed $1.75 \%$ of the body weight of the fish, reflecting the $25 \%$ adjustment volume of the total 7\% swim bladder volume [7]. Experimental evidence indicated that bluegills (Lepomis cyanellus) could maintain neutral buoyancy when burdened with weights of up to $2 \%$ of the weight the fish in air [8], and subsequent authors argued that weights of transmitters in water should be less than $1.5 \%$ of the fish weight [9]. In 1983, Winter [10] recommended that as a rule of thumb, fish should not be tagged with transmitters that weighed more than $1.25 \%$ in water or $2 \%$ in air of the fish's weight out of water. In support of this guideline, Mellas et al. [4] reported no difference in swimming performance of rainbow trout implanted with tags that were $<1.7 \%$ body weight. Though intended as a 'rule of thumb', this recommendation was republished by the American Fisheries Society in 1996 [11] and is now widely accepted and used in many studies.

Despite its ubiquity, several studies have challenged the $2 \%$ rule and shown that much heavier tags can be used without detriment to the physiology or swimming performance of the fish. In one study of juvenile rainbow trout (Oncorhynchus mykiss), intraperitoneal implantation of transmitters that weighed $6 \%$ to $12 \%$ of the fish's body weight in air did not adversely affect the critical swimming velocity [12]; however, physiological measures of stress were not quantified. Additionally, studies of pre-smolt coho salmon (O. kisutch) tagged with internal tags weighing up to $8 \%$ body mass and observed for 300 days showed no significant effect of tag size on growth, swimming performance, or likelihood of survival in the wild [13].

In addition to the impacts that heavier tags may have on fish physiology and performance, researchers also need to minimize the possibility of loss of expensive tags due to tag expulsion or outright mortality of tagged fishes. In one study of Chinook salmon (O. tshawytscha) smolts, mortality was low and there was negligible loss of tags weighing $2.6 \%$ to $11.5 \%$ body weight for the first month post tagging; however, tag retention decreased significantly in some groups of tagged fish in subsequent months [14].
Tag size is influenced by several factors including the sizes of the battery and the acoustic transducer. Larger batteries permit tags to have longer functional lives, a useful feature in long-term studies, and larger transducers are generally more efficient at producing sounds in the preferred frequency range, which decreases demand on the battery and increases tag life. However, researchers using acoustic tags generally desire that the tags produce the highest intensity signal possible so that it propagates long distances and increases the likelihood of detection. Functional tag size, therefore, represents a tradeoff between the competing demands of maximizing battery life and maximizing the desired detection distance while avoiding placing excessive burden on the fish [14]. Historically, acoustic tags have been fairly large, which has limited the use of this technology to larger species or adult life stages; however, advances in miniaturization and battery technology have permitted tag manufacturers to create functional tags as small $5 \mathrm{~mm}$ diameter and $12 \mathrm{~mm}$ in length, weighing $0.65 \mathrm{~g}$ (for example, V5, VEMCO, Bedford, Nova Scotia, Canada). These advances have permitted researchers to use acoustic telemetry on earlier life stages such as sub-yearling salmonids $[15,16]$ and smolts [16-18].

Stress has been shown to dramatically alter fish physiology and reduce growth $[19,20]$. The integrated physiological stress response starts with a primary response in which catecholamines and corticosteroids are released into the blood stream shortly after the onset of a stressor [19]. The release of these hormones and neuromodulators induces a secondary response that includes metabolic changes (for example, increases in plasma glucose and lactate), osmoregulatory disturbances (plasma ion imbalance), hematological changes (packed red blood cell volume or hematocrit (HCT)), and changes to immune system function $[19,21]$. The stress response is an adaptive mechanism that permits fish to react to and manage changing conditions that alter their normal state; however, severe or chronic stressors can make it difficult for fish to return to homeostasis and become maladaptive. The mobilization of energy substrates and relocation of energy away from growth and reproduction, and suppressive effects on immune functions [19] can eventually lead to long-term organismal impacts. These tertiary responses include changes in performance such as reduced growth, swimming capacity, reproductive capacity, or disease resistance [21]. Further, if the health and performance of a fish is impaired as a result of elevated stress, it can be immediately debilitating and may also increase the vulnerability to subsequent challenges such as fleeing from predators or swimming upstream [22].

The severity, duration, and organismal impacts of stress associated with the internal tagging procedures often used in the field are poorly understood, especially in relatively 
small-sized fish species [12]. However, thanks to the ongoing miniaturization of acoustic telemetry transmitters, this technology is increasingly being applied to smaller fish species or life-stages [12], and, due to their small size, it is these fish that are most likely close to the theoretical $2 \%$ tag size limit. The objective of this study was to determine the impacts of exceeding the $2 \%$ rule in one such small, stream-dwelling, migratory species, brook trout (Salvelinus fontinalis). Mortality, tag retention, swimming performance, and physiological indicators of stress were quantified in order to determine if: (1) mortality increased with tag size; (2) tag retention decreased with tag size; (3) tags greater than $2 \%$ body weight affected the swimming performance of brook trout; and (4) if there was a relationship between tag size and physiological indicators of stress. Brook trout were selected for this study because they are representative of the kinds of fish that are now being studied with acoustic telemetry [23] due to their size, migratory behavior, and conservation interest.

\section{Results}

Brook trout were initially distributed in three experimental groups: sham (surgery only), light (6.5-g tags), and heavy (12-g tags) (Table 1). No mortality was observed throughout the experiment. Two fish (11.8\%) from the light tag treatment group lost their tags, whereas 12 fish (80\%) from the heavy tag treatment lost tags, a difference that was statistically significant $(P<0.001$, Fisher's exact test). One tag was lost in each treatment group within the first 2 days post tagging, and all tags were lost by day 14 (Figure 1). The two fish in the light group that lost tags had also lost their sutures by day 14, but the sutures of 10 of the fish that lost tags from the heavy group were still intact and the incision was well-healed. One fish in the sham treatment was observed without sutures; however, it had not lost its PIT tag and the incision was closed, suggesting suture loss occurred after the wound healed. There was no correlation between tag loss and fork length of fish $(\mathrm{r}=0.07, \mathrm{n}=47, P=0.64)$. On the final handling day of the experiment, one additional fish from the light tag group was observed to have a large, inflamed, open wound that had not healed. It is likely that this fish would have lost its tag shortly thereafter. Though it was not included in the tag loss group for this analysis, it was excluded from all further analyses due to its abnormally poor condition.

Table 1 Summary of experimental treatment groups

\begin{tabular}{lllll}
\hline Treatment & $\mathbf{N}$ & $\mathbf{L}_{\mathbf{f}}(\mathbf{c m})$ & Mass $(\mathbf{g})$ & Tag \% body weight \\
\hline Sham & 15 & $21.0(2.0)$ & $134.2(36.1)$ & - \\
Light & 17 & $21.5(1.6)$ & $144.2(32.4)$ & $4.7(1.1)$ \\
Heavy & 15 & $21.1(1.0)$ & $131.4(17.9)$ & $9.3(1.1)$ \\
\hline
\end{tabular}

Mean $( \pm \mathrm{SD})$ fork length $\left(\mathrm{L}_{f}\right)$ and mass of brook trout in each experimental treatment on the day of internal tag implantation. Dummy tags weighed either $6.5(0.4)$ or $12.0(0.2)$ grams in air.

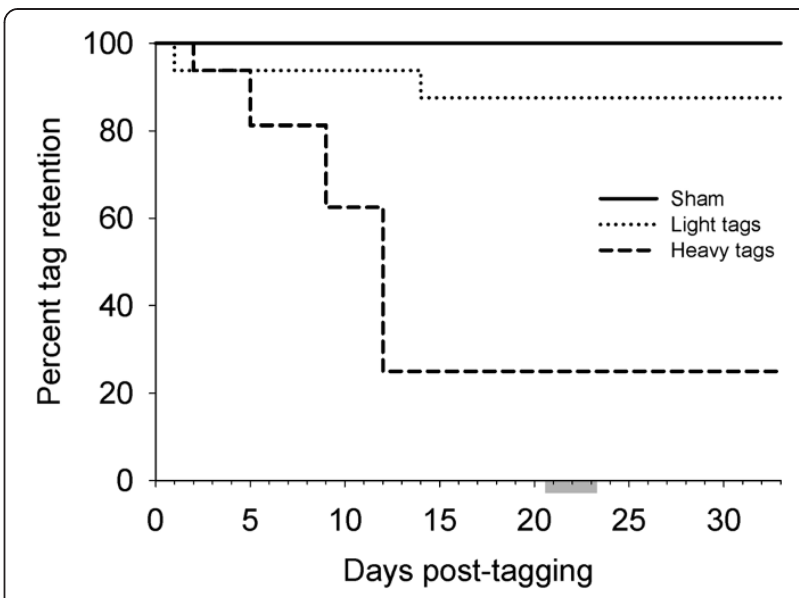

Figure 1 Percent of fish that retained tags in the three treatments from tagging (day 0 ) to the final sampling day (day 33). Solid line indicates the sham control group, dotted line indicates fish with tags $<7 \%$ body mass, and dashed line indicates fish with tags $>7 \%$ body mass. Swimming trials were conducted on a subset of the fish on days 21 to 23 (gray bar on $x$ axis).

A second fish from the heavy tag group was in very poor condition and visibly different from the remaining fish. It is not known if this ill health was due to the experimental treatment so it was removed from all further analyses.

At the time of the swim trial, the brook trout were larger than initially anticipated and the experimental flume was not able to generate sufficient water velocity to exceed the swimming capacity of all of the fish. Fourteen out of the 22 fish that underwent swimming performance testing did not fail at the maximum swimming speed that the flume could generate $\left(130 \mathrm{~cm} \mathrm{~s}^{-1}\right)$; however, fish from all treatment groups were observed swimming in excess of six body lengths $(\mathrm{bl}) \cdot \mathrm{s}^{-1}$. There were no significant differences in the observed swimming speeds between treatment groups (Table 2, ANOVA: $\mathrm{F}_{3,18}=1.82, P>0.05$ ).

Fish that lost heavy tags were included as a fourth treatment group in subsequent analyses in order to examine the effects that shedding an internal tag had on the fish. As a result of this, the final treatment groups were: sham $(\mathrm{N}=15)$, light tags $(\mathrm{N}=14)$, heavy tags $(\mathrm{N}=3)$, and lost tags $(\mathrm{N}=11)$. None of the response variables varied as a function of fork length (ANCOVA, $P>0.05$ ). The results $( \pm S E M)$ of all hematological measurements are summarized in Table 2. There were no significant differences between groups for plasma glucose, lactate, chloride, cortisol, and HCT (ANOVA, $P>0.05$ ).

The difference in specific growth rates (SGR) based on fork length was significant between treatments during the first time interval (between tagging and the swimming performance trials, ANOVA: $\mathrm{F}_{3,39}=3.24, P=0.03$ ). Pairwise comparisons with Tukey's post hoc test were not significant, however, possibly due to the small sample size of 
Table 2 Summary of biochemistry and swimming trial results

\begin{tabular}{lllllllll}
\hline Group & $\mathbf{N}_{\mathbf{b}}$ & Chloride $(\mathbf{m M})$ & Glucose $(\mathbf{m M})$ & Lactate $(\mathbf{m M})$ & Cortisol $\left(\mathbf{n g} \cdot \mathbf{~ m l}^{-\mathbf{1}}\right)$ & $\mathbf{H C T}$ & $\mathbf{N}_{\mathbf{u}}$ & $\mathbf{U}_{\text {crit }}\left(\mathbf{b l} \cdot \mathbf{s}^{-1}\right)$ \\
\hline Sham & 15 & $123.04(1.03)$ & $3.94(0.10)$ & $2.49(0.19)$ & $1.89(0.29)$ & $29.3(0.8)$ & 8 & $5.5(0.2)$ \\
Light & 14 & $121.24(0.90)$ & $3.95(0.20)$ & $2.35(0.22)$ & $2.61(0.72)$ & $30.9(1.2)$ & 9 & $5.5(0.2)$ \\
Heavy & 3 & $122.00(1.12)$ & $4.03(0.16)$ & $1.81(0.08)$ & $2.22(1.04)$ & $29.9(1.5)$ & 3 & $5.9(0.6)$ \\
Lost & 11 & $121.86(0.66)$ & $3.92(0.24)$ & $1.85(0.23)$ & $1.47(0.45)$ & $29.6(1.4)$ & 2 & $6.7(0.1)$ \\
\hline
\end{tabular}

Mean ( \pm SEM) levels of circulating chloride ions, glucose, lactate and cortisol in blood plasma HCT (\% packed cell volume) recorded on the final day of sampling, 33 days post tagging. $\mathrm{N}_{\mathrm{b}}$ is the number of samples used in the analysis of blood biochemistry, $\mathrm{N}_{\mathrm{u}}$ is the number of fish in each group that were used in flume swimming trials conducted on days 21 to 23 post tagging, $U_{\text {crit }}$ represents maximum recorded swimming velocity. No significant differences were found in any variables between treatment groups (ANOVA, $P>0.05$ ).

the heavy group, and when the heavy group was removed from the analysis, there was no significant difference between the remaining treatments (ANOVA: $\left.\mathrm{F}_{2,37}=3.075, P>0.05\right)$. During the first time interval, SGR was lower for all fish that had received a heavy tag, in both those that retained the tag and those that lost it, with the lowest growth recorded in the fish that retained heavy tags (Figure 2). There was no difference in SGR between treatment groups within the second time interval (between swimming trials and final sampling, ANOVA: $F_{3,39}=0.60$, $P=0.62)$. SGR was higher during the second time interval than in the first interval in the light, heavy, and lost groups, with significantly increased growth observed in both the heavy (Paired $t$-test: $\mathrm{t}_{2}=-5.265, P=0.03$ ) and lost group (Paired $t$-test: $\mathrm{t}_{10}=-3.672, P=0.01$ ). There was no correlation between any measured parameters and the number of days after tag loss in the shed tag group $\left(\mathrm{R}^{2}=0.0005-0.0102\right)$.

\section{Discussion}

The masses of the dummy tags used in this study were selected based on previously published research that

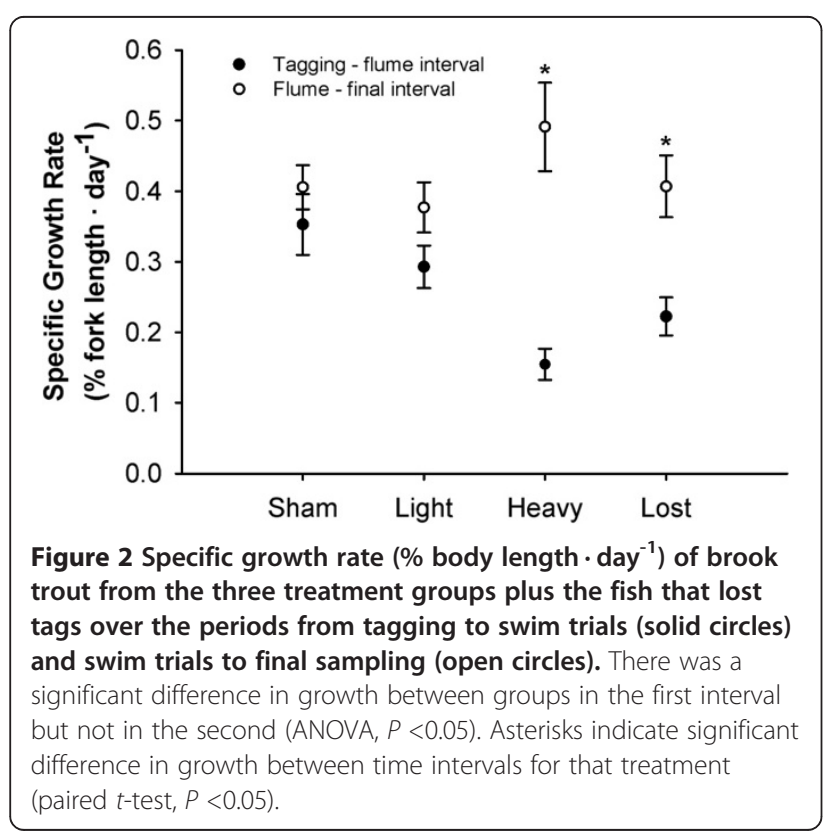

reported no impact to critical swimming velocity in rainbow trout implanted with tags that weighed between $6 \%$ and $12 \%$ body weight in air [12]. Tags of that mass represent a large proportion of the fish's body weight, and while we anticipated similar swimming performance in brook trout, we hypothesized that fish carrying that much mass internally likely would suffer other physiological impacts because the tag itself would be a significant stressor. One of the most unexpected findings of this study was the high rate of tag loss, with most of the fish in the heavy tag treatment losing tags less than 2 weeks after insertion. Tag expulsion suggests either a failure of the sutures that closed the wound or some form of transintestinal or transabdominal active expulsion [24,25]. Both of the fish in the light treatment that lost their tags, and four of the fish in the heavy treatment, had no sutures present, suggesting the loss of the dummy tag through the site of the incision. Observations during daily tank maintenance and feeding noted that some fish remained near the bottom of the tank, suggesting abrasion of the sutures may have played a role in tag loss. The bottoms of the tanks used in this study were bare fiberglass, and fish living in the wild in complex, rocky, swiftflowing streams may be at even greater risk of tag loss through the incision. Interestingly, the majority of fish that lost their tag in the heavy treatment still had their sutures present suggesting some form of active expulsion. Though not common in the literature, transintestinal tag expulsion, in which the tag is engulfed by the intestine before being passed via the cloaca, has been described in channel catfish (Ictalurus punctatus) [7,24] and rainbow trout [26] and may have occurred here too. In those studies, the authors noted encapsulation of the internal tag by a fibrous capsule of granulation tissue prior to expulsion. Unfortunately, close examination of the body cavity was not conducted when dummy tags were recovered at the end of this experiment, so it is not known if this process was occurring in this study. The large differences in tag expulsion between the two treatment groups indicates that tag loss was a result of the mass of the tags rather than suture type, pattern, or knot, or the presence of the tag alone. These results suggest that, at least in brook trout, tags in excess of $7 \%$ body mass in air have a high probability of being lost, which would severely impact the results of a telemetry study. 
It is imperative that internal acoustic tags have no effect on the swimming ability of the tagged fish, all the more so in salmonids because of their migratory behaviors and use of shallow, high velocity upriver spawning habits. Many of the fish in this study were able swim at the maximum velocity we could generate in our flume, so we were unable to calculate critical swimming velocity for each group; however, other authors have reported critical swimming velocities for brook trout in excess of $7 \mathrm{bl} \cdot \mathrm{s}^{-1}[27,28]$, which compares with our findings. There was no apparent difference in swimming performance between any of the groups in this study, which suggests that even heavy tags had little measurable impact on swimming performance. These results support the findings in earlier studies $[12,13]$ and indicate that tags substantially greater than $2 \%$ body weight should not have any significant effects on the migration and spawning ability of brook trout.

The internal tagging procedure is a stressful process for any fish. In addition to the surgery, the fish is handled, air-exposed, and anesthetized inducing alterations of various biochemical parameters associated with the stress response [29]. However, aside from the stress associated with standard tagging procedures, the results of this study indicate that the insertion of tags greater than $2 \%$ body weight did not lead to significant differences in plasma lactate, glucose, chloride, cortisol or HCT between sham and experimental fish. In this study, blood samples were collected 33 days after tags were inserted. It is likely that these parameters were elevated shortly after tagging and it is possible that there were differences between groups at that time, but after 1 month the fish appear to have recovered and there was no evidence of chronic stress. Interestingly, even the fish that had shed their tag showed no long-term effects, despite the trauma of expelling the tags.

There was an apparent effect of inserting tags on SGR during the first few weeks after tagging, with the fish tagged with heavy tags growing at approximately half the rate of the control sham treatment. These fish appear to have had the highest rate of growth in the later time interval, suggesting there may have been compensatory growth after recovery from the acute stress of tagging [30]. It seems likely that any perturbation in growth is due to the extreme weight of the tags since no such impact was noted in fish tagged in the light treatment using dummy tags of identical external dimensions. When these observations are combined with the large rate of tag expulsion in the weeks after tagging, it is apparent that tags in excess of $7 \%$ body mass put an acute strain on the physiology of the fish. However, the fish either rapidly eject the foreign object or acclimate and compensate for its presence, and tags less than 7\% body mass - which is a substantial relative mass - cause no apparent insult to normal physiology and performance.

\section{Conclusions}

The results of this study suggest that the ' $2 \%$ rule' is a highly conservative guideline, at least in brook trout. Tags considerably greater than $2 \%$ body weight did not significantly affect survival or swimming performance, and there was no evidence of chronic stress as a result of the tagging procedure or the tags. The most significant problem related to using heavy tags was retention, with significant tag loss observed in tags greater than $7 \%$ body weight. It is unclear where the threshold for increased tag loss occurs, and it is also possible that there are differences between species with different body shapes. Although additional work is warranted in order to form a general guideline for tag-to-fish mass ratio across species, this study suggests that the $2 \%$ rule can be safely extended up to $7 \%$ in this species, without causing undue stress, mortality, or tag loss.

\section{Methods}

Forty-eight adult Nashua-strain brook trout were acquired from the Quinebaug Valley Trout Hatchery in Central Village, CT, USA. The trout were kept in three 1.5-m diameter holding tanks supplied with flow-through Connecticut River water warmed to $10^{\circ} \mathrm{C}$. Experimental treatments were distributed between holding tanks. Fish were fed twice daily with 6-mm pellet feed (BioTrout, BioOregon, Warrenton, OR, USA). Fork length $\left(\mathrm{L}_{\mathrm{f}}\right)$, total length $\left(\mathrm{L}_{\mathrm{t}}\right)$, and weight (WT) were measured three times for each fish: during initial tagging, after the swim performance test, and on the final day of sampling. Specific growth rate was calculated using the formula $\frac{\operatorname{Ln} T_{2}-\operatorname{Ln} T_{1}}{\text { Days }} \cdot 100$ where $T$ is the time in days. All fish were euthanized at the conclusion of the experiment to retrieve tags. The experiment consisted of three phases: tagging (19 December 2012), swimming performance trials (9 to 11 January 2013), and final sampling (21 January 2013).

\section{Experimental treatment}

Fish were separated into three experimental groups: control sham, light tag (6.5-g, <7\% body weight), and heavy tag (12.0-g, $>7 \%$ body weight) (Table 1). Sham fish underwent the same surgical and handling procedures as the tagged fish but did not receive a dummy tag. Light and heavy tagged fish received dummy internal acoustic tags constructed of cylindrical lead weights encased with an inert plastic coating similar to the technique described by Mosely and Castleberry [31]. Dummy tags measured $7 \mathrm{~mm}$ in diameter by $23 \mathrm{~mm}$ in length and were modeled on the dimensions of a standard tag produced by one of the major manufacturers of acoustic tags (V7, Vemco, Bedford, Nova Scotia, Canada). Fish were anesthetized for at least $90 \mathrm{~s}$ in $40 \mathrm{mg} \mathrm{L}^{-1} \mathrm{MS}-222$ buffered with $\mathrm{Na}_{2} \mathrm{CO}_{3}$ until equilibrium was lost. Fish 
were weighed, measured for total and standard length, and then inverted on a surgical table with the anterior end covered loosely with a wet chamois. A $1-\mathrm{cm}$ ventral incision was made anterior of the insertion of the pelvic fins. Fish from all three treatments also received a passive integrated transponder $(8 \times 1.4 \mathrm{~mm}$ FDX-B 'Skinny' PIT Tag, Oregon RFID, Portland, OR, USA) through the same incision to enable identification of individuals. The PIT tags weighed $0.036 \mathrm{~g}$ (between $0.2 \%$ and $0.5 \%$ of the dummy tag mass). In small salmonids, the impact of PIT tags has been negligible [32-34] therefore their weight was not included in tag burden calculations. Dummy and PIT tags were inserted in the experimental groups and the incisions of all fish were closed with two interrupted figure-eight sutures of absorbable 4-0 chromic gut. Lastly, inert latex paint in one of three different colors was injected into a ray of the anal fin to further aid in identification of treatment groups. The morphometric measurements, surgery, and fin marking tasks were performed in sequence by three experienced members of the research team, and the same individual conducted each task for all fish to ensure consistency of handling method and duration. Fish were placed into a recovery tank until equilibrium was regained and then were placed back into the three holding tanks with an even distribution of treatment groups in each tank.

\section{Swimming trials}

After a 21-day post-surgery acclimation period, fish from each holding tank were placed in a Brett-style swimming flume in the manner of Brown [12]. It was initially intended that half of the fish from each treatment would be tested in the flume; however, due to unexpected levels of tag loss in the heavy treatment, there were only three fish with heavy tags remaining when the swimming trials started. All heavy treatment fish were tested in the flume, and two fish that lost tags were included as well because at the time it was not entirely clear which fish had lost tags (this was later verified by dissection). Fish that were not swum in the flume were measured for length and weight and returned to their tanks. Three trials, one for each holding tank, were performed over a 3-day period. Trials were conducted at the same time each day. The swim flume was supplied with ambient Connecticut River water at the same temperature as the holding tanks. Fish were allowed to acclimate in the flume with a water velocity of $5-\mathrm{cm} \mathrm{s}^{-1}$ for $2.5 \mathrm{~h}$ before the trials began. After the acclimation period, water velocity was increased by $10 \mathrm{~cm} \mathrm{~s}^{-1}$ every $20 \mathrm{~min}$ up to the maximum speed of the flume $\left(130 \mathrm{~cm} \mathrm{~s}^{-1}\right)$. Fish were forced to swim until they were fully fatigued and impinged on the rear screen of the flume for a period of $10 \mathrm{~s}$, or until the maximum speed of $130 \mathrm{~cm} \mathrm{~s}^{-1}$ was sustained for $20 \mathrm{~min}$ without failure.
Maximum observed swimming speed was calculated using the formula developed by Brett [35]:

$$
U \text { crit }=U \mathrm{f}+\frac{T f}{T i} \cdot U i
$$

where $U_{f}$ is the highest speed that the fish was able to maintain for the entire interval, $T_{f}$ is the time the fish was able to swim at the final speed, $T_{i}$ is the time interval (20 min), and $U_{\mathrm{i}}$ is the speed increment by which the velocity was raised. After the swim trials, fish were rapidly anesthetized, length and weight recorded, and then returned to their original holding tanks.

\section{Physiological stress assays}

Ten days after the final swim flume trials, fish were rapidly anesthetized, measured for length and weight, and $1 \mathrm{~mL}$ of blood was collected from every fish through caudal puncture. All blood samples were collected within $5 \mathrm{~min}$ of initial disturbance of the tank. HCT was measured and blood was centrifuged at 4,750 rpm for $5 \mathrm{~min}$. Plasma was separated and frozen immediately at $-80^{\circ} \mathrm{C}$ for later analysis. Plasma cortisol levels were measured via direct enzyme immunoassay [36]. Plasma glucose levels were measured through the enzymatic coupling with hexokinase and glucose-6-phosphate dehydrogenase [37]. Plasma lactate was measured through a reduction of nicotinamide adenine dinucleotide with lactate dehydrogenase [38]. Plasma chloride was determined in $20 \mu \mathrm{L}$ volumes by the coulometric silver titration method using a chloridometer (SAT-500, DKK-TOA Corporation, Tokyo, Japan).

\section{Statistical analysis}

Differences in the proportion of tags lost between light and heavy tags was tested using Fisher's exact test. The effect of light and heavy tags on the measured variables was examined using ANCOVA with fork length as the covariate. When the covariate had no effect, the data were analyzed using one ANOVA. Paired t-tests were conducted for each treatment to test for differences in growth between time intervals. All statistical tests were performed using SPSS (v. 19, IBM Corp., Armonk, NY, USA) and significance was accepted at $\alpha=0.05$.

\section{Competing interests}

The authors declare that they have no competing interests.

\section{Authors' contributions}

Both authors contributed equally to the design, conduct, and analysis of this study, and to the preparation of this manuscript. Both authors read and approved the final manuscript.

\section{Acknowledgements}

This study would not have possible without the help and resources provided by the McCormick Fish Environmental Physiology lab at the USGS Conte Anadromous Fish Research Center, Turners Falls, MA, USA. Particular thanks to S. McCormick for his support and guidance throughout the project, A. Regish for conducting the cortisol assays, and M. O'Dea, A. Weinstock, and 
M. Nichols. Many thanks to P. Vogt of the UNH Ecophysiology and Behavior Lab for his time and efforts both in and out of the laboratory. Finally, thanks to S. Bullock of Salty Bugger Lures for his generous donation of materials to construct the dummy acoustic tags. This paper is dedicated to our friend and colleague Michael F. O'Dea (1962-2014).

Received: 9 July 2014 Accepted: 4 October 2014

Published: 28 October 2014

\section{References}

1. Trefethen PS: Sonic Equipment for Tracking Individual Fish. Special Scientific Report - Fisheries Number 179. Washington, DC: US Dept. of the Interior, Fish and Wildlife Service; 1956.

2. Cooke SJ, Midwood JD, Thiem JD, Klimley P, Lucas MC, Thorstad EB, Eiler J, Holbrook C, Ebner BC: Tracking animals in freshwater with electronic tags: past, present and future. Animal Biotelem 2013, 1:5.

3. Jepsen N, Schreck C, Clements S, Thorstad E: A Brief Discussion on the $2 \%$ tag/Bodymass Rule of Thumb. In Aquatic Telemetry: Advances and Applications - Proceedings of the Fifth Conference on Fish Telemetry: 9-13 June 2005; Ustica, Italy. Edited by Spedicato MT, Lembo G, Marmulla G. Rome: FAO; 2005:255-259.

4. Mellas EJ, Haynes JM: Swimming performance and behavior of rainbow trout (Salmo gairdneri) and white perch (Morone americana): effects of attaching telemetry transmitters. Can J Fish Aquat Sci 1985, 42:488-493.

5. Brown RS, Oldenburg EW, Seaburg AG, Cook KV, Skalski JR, Eppard M, Deters KA: Survival of seaward-migrating PIT and acoustic-tagged juvenile Chinook salmon in the Snake and Columbia Rivers: an evaluation of length-specific tagging effects. Animal Biotelem 2013, 1:8

6. Alexander R: Physical aspects of swimbladder function. Biol Rev Camb Philos Soc 1966, 41:141-176.

7. Summerfelt RC, Mosier D: Transintestinal expulsion of surgically implanted dummy transmitters by channel catfish. Trans Am Fish Soc $1984,113: 760-766$

8. Gallepp GW, Magnuson JJ: Effects of negative buoyancy on the behavior of the bluegill, Lepomis macrochirus Rafinesque. Trans Am Fish Soc 1972, 101:507-512.

9. Ross MJ, McCormick JH: Effects of external radio transmitters on fish Prog Fish-Cult 1981, 43:67-72.

10. Winter J: Underwater Biotelemetry In Fisheries Techniques. Edited by Nielsen LA, Johnson DL. Bethesda, MD: American Fisheries Society; 1983:371-395.

11. Winter J: Advances in Underwater Biotelemetry. In Fisheries Techniques. 2nd edition. Edited by Murphy BR, Willis DW. Bethesda, MD: American Fisheries Society; 1996:555-590

12. Brown RS, Cooke SJ, Anderson WG, McKinley RS: Evidence to challenge the "2\% rule" for biotelemetry. N Am J Fish Manag 1999, 19:867-871.

13. Chittenden CM, Butterworth KG, Cubitt KF, Jacobs MC, Ladouceur A, Welch DW McKinley RS: Maximum tag to body size ratios for an endangered coho salmon (O. kisutch) stock based on physiology and performance. Env Biol Fish 2009, 84:129-140

14. Rechisky EL, Welch DW: Surgical implantation of acoustic tags: influence of tag loss and tag-induced mortality on free-ranging and hatchery-held spring Chinook (O. tschawytscha) smolts. In PNAMP Special Publication: Tagging, Telemetry and Marking Neasures for Monitoring Fish Populations-A Compendium of new and Recent Science for use in Informing Technique and Decision Modalities. Edited by Wolf KS, O'Neal JS. Duvall, WA: Pacific Northwest Aquatic Monitoring Partnership; 2009:1-96.

15. Skalski JR, Eppard MB, Ploskey GR, Weiland MA, Carlson TJ, Townsend RL: Assessment of subyearling Chinook Salmon survival through the federal hydropower projects in the main-stem Columbian river. N Am J Fish Manag 2014, 34:741-752

16. Steig TW, Skalski JR, Ransom BH: Comparison of Acoustic and PIT Tagged Juvenile Chinook, Steelhead and Sockeye Salmon (Oncorhynchus, spp.) Passing Dams on the Columbia River, USA. In Proceedings of the Fifth Conference on Fish Telemetry: 9-13 June 2003; Ustica, Italy. Edited by Spedicato MT, Lembo G, Marmulla G. Rome: FAO; 2005:275-286.

17. del Villar-Guerra D, Aarestrup K, Skov C, Koed A: Marine migrations in anadromous brown trout (Salmo trutta). Fjord residency as a possible alternative in the continuum of migration to the open sea. Ecol Fresh Fish 2014, 23:594-603.
18. Welch DW, Boehlert GW, Ward BR: POST- the Pacific Ocean salmon tracking project. Oceanol Acta 2003, 25:243-253.

19. Bonga SW: The stress response in fish. Physiol Rev 1997, 77:591-625.

20. Pickering AD: Stress and the suppression of somatic growth in teleost fish. In Progress in Clinical and Biological Research, Volume 342: Progress in Comparative Endocrinology. Edited by Epple A, Scanes CG, Stetson MH. New York: Wiley-Liss; 1990:473-479.

21. Barton BA: Stress in fishes: a diversity of responses with particular reference to changes in circulating corticosteroids. Integr Comp Biol 2002, 42:517-525.

22. Schreck C: Stress and compensation in teleostean fishes: response to social and physical factors. In Stress and Fish. Edited by Pickering AD. London: Academic; 1981:295-321.

23. Curry RA, Sparks D, van de Sande J: Spatial and temporal movements of a riverine brook trout population. Trans Am Fish Soc 2002, 131:551-560.

24. Marty GD, Summerfelt RC: Pathways and mechanisms for expulsion of surgically implanted dummy transmitters from channel catfish. Trans Am Fish Soc 1986, 115:577-589.

25. Jepsen N, Koed A, Thorstad EB, Baras E: Surgical implantation of telemetry transmitters in fish: how much have we learned? Hydrobiologia 2002, 483:239-248.

26. Chisholm IM, Hubert WA: Expulsion of dummy transmitters by rainbow trout. Trans Am Fish Soc 1985, 114:766-767.

27. Peterson R: Influence of fenitrothion on swimming velocities of brook trout (Salvelinus fontinalis). J Fish Board Can 1974, 31:1757-1762.

28. McDonald DG, McFarlane WJ, Milligan CL: Anaerobic capacity and swim performance of juvenile salmonids. Can J Fish Aquat Sci 1998, 55:1198-1207.

29. Mazeaud MM, Mazeaud F, Donaldson EM: Primary and secondary effects of stress in fish: some new data with a general review. Trans Am Fish Soc 1977, 106:201-212.

30. Ali M, Nicieza A, Wootton RJ: Compensatory growth in fishes: a response to growth depression. Fish Fish 2003, 4:147-190.

31. Moseley KR, Castleberry SB: Assessment of subcutaneously implanted reflector tags for relocating mole salamanders (Ambystoma talpoideum). GA J Sci 2005, 63:91-96.

32. Ombredane D, Bagliniere $\mathrm{LL}$, Marchand F: The effects of passive integrated transponder tags on survival and growth of juvenile brown trout (Salmo trutta L.) and their use for studying movement in a small river. Hydrobiologia 1998, 371/372:99-106.

33. Gries $\mathrm{G}$, Letcher $\mathrm{BH}$ : Tag retention and survival of age- 0 Atlantic salmon following surgical implantation with passive integrated transponder tags. N Am J Fish Manag 2002, 22:219-222.

34. Larsen MH, Thorn AN, Skov C, Aarestrup K: Effects of passive integrated transponder tags on survival and growth of juvenile Atlantic salmon Salmo sala. Animal Biotelem 2013, 1:19.

35. Brett J: The respiratory metabolism and swimming performance of young sockeye salmon. J Fish Board Can 1964, 21:1183-1226.

36. Carey JB, McCormick SD: Atlantic salmon smolts are more responsive to an acute handling and confinement stress than parr. Aquaculture 1998, 168:237-253.

37. Slein M: D-Glucose Determination With Hexokinase and Glucose-6Phosphate Dehydrogenase. In Methods of Enzymatic Analysis. Edited by Bergmeyer HU. New York: Academic; 1963.

38. Marbach EP, Weil MH: Rapid enzymatic measurement of blood lactate and pyruvate use and significance of metaphosphoric acid as a common precipitant. Clin Chem 1967, 13:314-325.

doi:10.1186/2050-3385-2-16

Cite this article as: Smircich and Kelly: Extending the 2\% rule: the effects of heavy internal tags on stress physiology, swimming performance, and growth in brook trout. Animal Biotelemetry 2014 2:16. 